3. Б.-Д. Дондоков, Д. З. Убонова. Формирование информационной базы проведения расчетов по загрязнению окружающей среды с использованием межотраслевой модели

Научная статья

УДК $330.44+330.15$

DOI 10.18101/2304-4446-2021-1-35-42

\title{
ФОРМИРОВАНИЕ ИНФОРМАЦИОННОЙ БАЗЫ ПРОВЕДЕНИЯ РАСЧЕТОВ ПО ЗАГРЯЗНЕНИЮ ОКРУЖАЮЩЕЙ СРЕДЫ С ИСПОЛЬЗОВАНИЕМ МЕЖОТРАСЛЕВОЙ МОДЕЛИ
}

\author{
(C) Дондоков Зорикто Бато-Дугарович \\ доктор экономических наук, главный научный сотрудник \\ dzorikto@mail.ru
}

(C) Убонова Дарима Зориктоевна

младший научный сотрудник

darimaub@mail.ru

Отдел региональных экономических исследований

Бурятский научный центр СО РАН

Россия, 670047, г. Улан-Удэ, ул. Сахьяновой, 8

\begin{abstract}
Аннотация. Статья посвящена вопросам формирования информационной базы проведения межотраслевых расчетов по загрязнению окружающей среды региона. Выявлена проблема недостаточной точности оценок антропогенного воздействия на Байкальскую природную территорию без учета отраслевых особенностей производства. Обоснована необходимость использования аппарата межотраслевого моделирования для повышения уровня детализации и обоснованности расчетов. Выявлены информационные проблемы подготовки региональных таблиц «затраты-выпуск». Приведены формулы расчета мультипликативных эффектов изменения объемов сброса сточных вод в поверхностные водоемы и выбросов в атмосферу загрязняющих веществ от стационарных источников по видам экономической деятельности. Показана ограниченность использования классической межотраслевой модели по оценке загрязнения окружающей среды рамками экономической деятельности, соответствующей ОКВЭД. Обоснована необходимость учета загрязнения окружающей среды домашними хозяйствами в рамках межотраслевой модели суммарных расходов.

Ключевые слова: межотраслевая модель; регион; Республика Бурятия; антропогенное воздействие; окружающая среда; вид экономической деятельности; статистические данные; таблицы «затраты-выпуск»; мультипликативные эффекты; эндогенные параметры; экзогенные параметры; домашние хозяйства.
\end{abstract}

\section{Для цитирования}

Дондоков 3. Б.-Д., Убонова Д. З. Формирование информационной базы проведения расчетов по загрязнению окружающей среды с использованием межотраслевой модели // Вестник Бурятского государственного университета. Экономика и менеджмент. 2021. № 1. С. 35-42.

Поиск баланса между экономическим развитием и охраной окружающей среды является одной из актуальных проблем современного общества. Наиболее остро эта проблема стоит для территорий с особым режимом природопользования, на которых запрещены или ограничены некоторые виды хозяйственной дея- 
тельности. К ним относится Байкальская природная территория (БПТ), на которой действуют достаточно жесткие экологические ограничения, связанные с необходимостью защиты окружающей среды на прилегающих к Байкалу местностях.

Проблемы взаимодействия экономического развития и охраны окружающей среды БПТ являются объектом исследований российских ученых. Разрабатываются предложения по механизмам внедрения компенсационных платежей за ущерб, наносимый экосистеме озера Байкал, и решению проблем социальноэкономического развития Байкальской природной территории [1]. Исследуются причины и следствия введения новых природоохранных ограничений на БПТ [2]. Рассматриваются эколого-экономические проблемы и конфликты в сфере землепользования, водопользования и рекреационной деятельности на Байкальской природной территории [3].

Отдельным направлением исследований является оценка антропогенного воздействия на окружающую природную среду БПТ. Проводится расчет экологического ущерба от загрязнения атмосферного воздуха стационарными источниками выбросов в муниципальных образованиях центральной экологической зоны [4]. Вместе с тем такие исследования выполнены в агрегированной форме без учета отраслевых особенностей производства, что существенно снижает возможности проведения детализированного анализа воздействия на природную среду. Кроме того, как правило, производится расчет только прямого загрязнения. Неучтенными остаются косвенные эффекты, возникающие в отраслях и смежных производствах, связанных производственно-кооперационными связями с производством указанного вида продукции, и обусловленные изменением объема ее конечного потребления. Например, загрязнение возникает не только при выпуске готовой продукции, но и в производстве комплектующих, полуфабрикатов, энергии и сырья. В сумме прямые и косвенные эффекты составляют мультипликативные эффекты.

Решение указанной проблемы видится в использовании в расчетах межотраслевых моделей, являющихся общепризнанным инструментом анализа и прогнозирования развития территориальных систем [5]. Эколого-экономическое моделирование в настоящее время является одним из ведущих направлений межотраслевых исследований. Наибольшее распространение получили межотраслевые модели с экологическим блоком EEIO (environmentally extended input-output analysis), используемые для анализа межотраслевого взаимодействия экономических и экологических процессов, включая использование земельных, водных и энергетических ресурсов [6], выбросы загрязняющих веществ [7], оценку экономических потерь и доходов в глобальных производственно-сбытовых цепочках [8]. Применение этих моделей позволяет повысить точность и обоснованность расчетов по оценке воздействия антропогенных факторов на экологическое состояние территории, а также оценить влияние возможных изменений экологических требований на развитие региона по видам экономической деятельности.

Межотраслевая модель оценки загрязнения окружающей среды включает два блока информационного массива: эндогенный и экзогенный. К эндогенным параметрам относятся базовые таблицы «затраты-выпуск» (далее - ТЗВ), а к экзо- 
3. Б.-Д. Дондоков, Д. З. Убонова. Формирование информационной базы проведения расчетов по загрязнению окружающей среды с использованием межотраслевой модели

генным - параметры, определяемые вне модели, включая показатели конечного потребления, а также удельные показатели загрязнения окружающей среды.

В основе классической региональной межотраслевой модели лежит баланс производства и распределения продукции по отраслям экономики (межотраслевой баланс), описываемый таблицей «затраты-выпуск»:

$$
X=A X+Y \text {, }
$$

где $X=\left(X_{j}\right)$ - вектор-столбец объемов валового выпуска товаров и услуг в регионе, который представляет собой суммарную стоимость товаров и услуг, являющихся результатом производственной деятельности единиц экономики региона в отчетном периоде;

$j$ - индекс вида экономической деятельности;

$E$ - единичная матрица порядка $n$;

A - матрица региональных коэффициентов прямых затрат (региональная технологическая матрица);

$A X$ - вектор-столбец промежуточного потребления, состоящего из стоимости товаров и услуг, которые потребляются в процессе производства;

$Y$ - вектор-столбец региональной конечной продукции.

Для проведения расчетов по межотраслевой модели определяется матрица полных экономических затрат региона $(E-A)^{-1}$, используемая для выявления объемов валового выпуска в регионе по формуле:

$$
X=(E-A)^{-1},
$$

где каждый коэффициент матрицы региона $(E-A)^{-1}$ представляет собой сумму прямых и косвенных затрат на всех стадиях производства, обусловленных выпуском единицы определенного вида продукции или услуги.

Основной проблемой проведения аналитических и прогнозных расчетов с использованием региональных межотраслевых моделей являются трудности в разработке разработки базовых региональных ТЗВ. Исследования по разработке адекватных таблиц «затраты-выпуск» стали отдельным направлением межотраслевого анализа на региональном уровне [9].

«Вечная» проблема регионализации межотраслевых балансов в условиях ограниченности исходных данных стимулировала развитие различных корректирующих техник, базирующихся на использовании национальных ТЗВ. Наиболее распространенной является методика расчета коэффициентов местоположения Флегга, использованной в исследованиях по разработке ТЗВ регионов Аргентины, Великобритании, Китая и Финляндии [10]. В ряде исследований, связанных с разработкой региональных и мультирегиональных ТЗВ, использовался метод перекрестной выборки скорректированного районирования Кроненберга с учетом структурных различий между региональной и национальной экономиками [11].

Большой опыт разработки таблиц «затраты-выпуск» имелся у отечественных статистиков и исследователей. В СССР межотраслевые балансы производства и распределения продукции впервые были разработаны по данным за 1959 г. Последняя работа была проведена на базе информации за 1987 г.

После распада Советского Союза наступил длительный перерыв в подготовке ТЗВ. В 2009 г. Правительством России было принято решение о разработке базовых таблиц «затраты - выпуск» за 2011 г. и в дальнейшем их подготовке на ре- 
гулярной основе 1 раз в 5 лет ${ }^{1}$. Размещение ТЗВ на сайте Росстата в 2016 г. стало большим импульсом в проведении межотраслевых исследований [12].

Вместе с тем прямое использование национальных ТЗВ при подготовке региональных таблиц «затраты-выпуск» связано с множеством проблем, включая вопросы оценки межрегиональных потоков продукции, учета деятельности подразделений территориально обособленных предприятий, различий в отраслевой структуре и т. п. В связи с этим большое значение имеет формирование региональных базовых ТЗВ, созданных на базе специальных статистических исследований.

В 2012 г. Правительством Республики Бурятия «в целях повышения качества стратегического планирования и прогнозирования социально-экономического развития Республики Бурятия на основе статистических данных, создания информационной базы для анализа, формирования статистической информации о межотраслевых связях и структурных пропорциях экономики» было принято решение о проведении научно-исследовательской работы «Разработка базовых таблиц "затраты-выпуск" для Республики Бурятия»² .

Были разработаны региональные таблицы «затраты-выпуск» по Республике Бурятия за 2011 г., сформированные в разрезе 50 видов экономической деятельности по всем крупным и средним предприятиям, а также на основе выборки по субъектам малого предпринимательства [13]. Эти таблицы являются основой информационной базы проведения межотраслевых расчетов. В настоящее время ведется работа по корректировке ТЗВ Республики Бурятия с учетом обновленных данных по региону и показателей таблицы «затраты-выпуск» России за 2016 год, а также переходом к новой редакции ОКВЭД, в соответствии с которой состав видов экономической деятельности увеличился с 17 до 21 .

В официальной статистической отчетности можно выделить два показателя загрязнения окружающей среды, представленных по видам экономической деятельности: показатели выбросов в атмосферу загрязняющих веществ от стационарных источников и показатели сброса сточных вод в поверхностные водоемы. По другим показателям в статистических сборниках приводится агрегированная информация без отраслевой детализации.

Для оценки уровня антропогенного воздействия на окружающую среду с использованием межотраслевой модели предварительно производится расчет удельных показателей загрязнения окружающей среды на единицу валового выпуска по видам экономической деятельности.

Расчет мультипликативных эффектов изменения объемов сброса сточных вод в поверхностные водоемы $(\Delta S)$ от изменения элементов региональной конечной продукции $(\Delta Y)$ определяется по следующей формуле:

$$
\Delta L=(E-A)^{-1} W \cdot \Delta Y,
$$

где $W=\left(W_{j}\right)$ - диагональная матрица удельных показателей сброса сточных вод в поверхностные водоемы;

$$
W_{j}=Q_{j} / X_{j}
$$

${ }^{1}$ Распоряжение Правительства РФ от 14 февраля 2009 г. № 201-р

${ }^{2}$ Об утверждении направлений и объемов финансирования научно-исследовательских работ в сфере экономики на 2013 год: постановление Правительства Республики Бурятия от 20 ноября 2012 года № 679. 
3. Б.-Д. Дондоков, Д. З. Убонова. Формирование информационной базы проведения расчетов по загрязнению окружающей среды с использованием межотраслевой модели

где $Q_{j}-$ объемы сброса сточных вод в поверхностные водоемы (млн м ${ }^{3}$ ).

Исходные и расчетные данные по сбросу сточных вод в поверхностные водоемы в Республике Бурятия приведены в табл. 1.

Основная часть сброса сточных вод в поверхностные водоемы $(79,7 \%)$ производится предприятиями по ВЭД «Обеспечение электрической энергией, газом и паром; кондиционирование воздуха». Следует отметить, что в силу специфики производства электроэнергии преобладают выбросы, осуществляемые Гусиноозерской ГРЭС.

Таблица 1

Показатели сброса сточных вод в поверхностные водоемы по Республике Бурятия в 2017 г.

\begin{tabular}{|c|c|c|}
\hline Вид экономической деятельности & $\begin{array}{c}\text { Объемы сброса } \\
\text { сточных вод } \\
\text { в поверхностные } \\
\text { водоемы, } \\
\text { млн м³ }\end{array}$ & $\begin{array}{c}\text { Удельные } \\
\text { показатели } \\
\text { сброса сточных вод } \\
\text { в поверхностные } \\
\text { водоемы, } \\
\text { м3/тыс. руб. }\end{array}$ \\
\hline Bсего & 617,4 & 1,513 \\
\hline $\begin{array}{l}\text { Сельское хозяйство, охота и лесное хозяйство; } \\
\text { рыболовство, рыбоводство }\end{array}$ & 4,3 & 0,209 \\
\hline Добыча полезных ископаемых & 7,4 & 0,290 \\
\hline Обрабатывающие производства & 0,0 & 0,000 \\
\hline $\begin{array}{l}\text { Обеспечение электрической энергией, газом и } \\
\text { паром; кондиционирование воздуха }\end{array}$ & 492,5 & 15,881 \\
\hline $\begin{array}{l}\text { Водоснабжение; водоотведение, организация } \\
\text { сбора и утилизации отходов, деятельность по } \\
\text { ликвидации загрязнений }\end{array}$ & 22,5 & 9,039 \\
\hline Строительство & - & 0,000 \\
\hline Транспортировка и хранение & 89,2 & 1,936 \\
\hline $\begin{array}{l}\text { Деятельность по операциям с недвижимым } \\
\text { имуществом }\end{array}$ & - & 0,000 \\
\hline Прочие виды экономической деятельности & 1,5 & 0,009 \\
\hline
\end{tabular}

* Составлено авторами по: Статистический ежегодник. 2019. Статистический сборник / Бурятстат. Улан-Удэ, 2019. С. 49.

Расчет мультипликативных эффектов изменения выбросов в атмосферу загрязняющих веществ от стационарных источников по видам экономической деятельности $(\Delta L)$ от изменения элементов региональной конечной продукции $(\Delta Y)$ определяется по следующей формуле:

$$
\Delta L=(E-A)^{-1} M \cdot \Delta Y,
$$

где $M=\left(M_{j}\right)$ - диагональная матрица удельных показателей выбросов в атмосферу загрязняющих веществ от стационарных источников;

$$
M_{j}=R_{j} / X_{j}
$$

где $R_{j}$ - объемы выбросов в атмосферу загрязняющих веществ от стационарных источников в ј-й отрасли (тыс. тонн). 
Исходные и расчетные данные по рассматриваемым показателям загрязнения по отраслям экономики Республики Бурятия приведены в табл. 2.

Таблица 2

Показатели выбросов в атмосферу загрязняющих веществ от стационарных источников по Республике Бурятия в 2017 г.

\begin{tabular}{|l|c|c|}
\hline \multicolumn{1}{|c|}{ Вид экономической деятельности } & \multicolumn{1}{|c|}{$\begin{array}{c}\text { Удельные } \\
\text { Объемы выбросов } \\
\text { загрязяющих веществ, } \\
\text { тыс. т }\end{array}$} & $\begin{array}{c}\text { показатели } \\
\text { выбросов } \\
\text { загрязняющих } \\
\text { веществ, } \\
\text { кг/млн р. }\end{array}$ \\
\hline Всего & 113,3 & 277,7 \\
\hline $\begin{array}{l}\text { Сельское хозяйство, охота и лесное хозяйство; } \\
\text { рыболовство, рыбоводство }\end{array}$ & 0,8 & 38,9 \\
\hline Добыча полезных ископаемых & 5,5 & 215,5 \\
\hline Обрабатывающие производства & 12,6 & 2644,1 \\
\hline $\begin{array}{l}\text { Обеспечение электрической энергией, газом и } \\
\text { паром; кондиционирование воздуха }\end{array}$ & 82,0 & 883,9 \\
\hline $\begin{array}{l}\text { Водоснабжение; водоотведение, организация } \\
\text { сбора и утилизации отходов, деятельность по } \\
\text { ликвидации загрязнений }\end{array}$ & 2,2 & 11,7 \\
\hline Строительство & 0,4 & 17,4 \\
\hline Транспортировка и хранение & 0,8 & 281,8 \\
\hline $\begin{array}{l}\text { Деятельность по операциям с недвижимым } \\
\text { имуществом }\end{array}$ & 2,8 & 37,2 \\
\hline Прочие виды экономической деятельности & 6,2 & 2,4 \\
\hline
\end{tabular}

* Составлено авторами по: Статистический ежегодник. 2019. Статистический сборник / Бурятстат. Улан-Удэ, 2019. С. 48.

Подавляющая часть выбросов в атмосферу загрязняющих веществ от стационарных источников (72,3 \%) производится предприятиями по ВЭД «Обеспечение электрической энергией, газом и паром; кондиционирование воздуха». По сути, загрязнение в основном осуществляют объекты энергетики Бурятии: УланУдэнские ТЭЦ-1 и ТЭЦ-2, Гусиноозерская ГРЭС. Вместе с тем, как отмечают специалисты регионального Управления Роспотребнадзора, основным источником загрязнения атмосферного воздуха в Улан-Удэ является разрастающийся частный сектор, состоящий из домов индивидуальной жилищной застройки с автономными угольными мини-котельными и дровяными печами ${ }^{1}$. Это определяет необходимость учитывать в расчетах дополнительное загрязнение воздуха, осуществляемое домашними хозяйствами.

1 Эксперты: загрязнения воздуха в Улан-Удэ связано с разрастанием частного сектора. URL: https://tass.ru/obschestvo/5958470 (дата обращения 27.07.2020). Текст : электронный. 
3. Б.-Д. Дондоков, Д. З. Убонова. Формирование информационной базы проведения расчетов по загрязнению окружающей среды с использованием межотраслевой модели

В силу этого вытекает следующий вывод: возможности классической межотраслевой модели по оценке загрязнения окружающей среды ограничены рамками экономической деятельности в соответствии с ОКВЭД (Общероссийским классификатором видов экономической деятельности). Учет загрязняющей деятельности домашних хозяйств возможен в межотраслевой модели суммарных расходов (ММСР), разработанной автором и включающей часть показателей потребительских расходов населения в состав эндогенных параметров [14]. Использование ММСР позволит обеспечить более высокий уровень точности расчетов загрязнения окружающей среды.

\section{Благодарность}

Исследование выполнено при финансовой поддержке РФФИ в рамках научного проекта № 20-010-00414

\section{Литература}

1. Потапов Л. В., Добровенский Ю. П. Проблемы охраны озера Байкал и социальноэкономического развития БПТ (эколого-экономический анализ) // Вестник Бурятского научного центра Сибирского отделения Российской академии наук. 2016. № 3(23). C. $151-158$.

2. Тулохонов А. К. О причинах и следствиях новых природоохранных ограничений на Байкальской природной территории // Известия Русского географического общества. 2018. T. 150. № 5. С. 48-55.

3. Эколого-экономические проблемы и конфликты природопользования в центральной экологической зоне Байкальской природной территории (Республика Бурятия) / А. С. Михеева, Л. Б. Ж. Максанова, Т. И. Абидуева, Т. Б. Бардаханова // География и природные ресурсы. 2016. № S5. С. 210-217.

4. Ботоева Н. Б. Аудит антропогенного загрязнения воздушной среды в центральной экологической зоне Байкальской природной территории // Управление экономическими системами: электронный научный журнал. 2018. № 9(115). URL: http://www.uecs.ru/ekonomika-prirodopolzovaniyz/item/5076-2018-08-30-13-27-11 (дата обращения: 10.01.2021). Текст : электронный.

5. Miller R. E., Blair P. D. Input-Output Analysis: Foundations and Extensions 2nd Ed. New York: Cambridge University Press, 2009. 749 p.

6. Yang, Y., Ingwersen, W., Hawkins, T., Srocka, M. and Meyer, D. (2017) USEEIO: A new and transparent United States environmentally-extended input-output model. Journal of Cleaner Production, Vol. 158, 308-318. https://doi.org/10.1016/j.jclepro.2017.04.150

7. Wiedmann, T., Wood, R., Minx, J. C., Lenzen, M., Guan, D. and Harris, R. (2010). A carbon footprint time series of the UK: Results from a multi-region input-output model. Economic Systems Research, 22(1). 19-42. https://doi.org/10.1080/09535311003612591

8. Cadarso, M.-A., Monsalve, F. and Arce, G. (2018) Emissions burden shifting in global value chains - winners and losers under multi-regional versus bilateral accounting. Economic Systems Research, 30 (4), 439-461. DOI: 10.1080/09535314.2018.1431768

9. Баранов А. О., Дондоков 3. Б.-Д., Слепенкова Ю. М. Построение и использование региональных межотраслевых моделей для анализа и прогнозирования развития экономики регионов // Идеи и идеалы. 2016. № 4, т. 2. C. 66-85. DOI: 10.17212/2075-0862-20164.2-66-85

10. Flegg, A., Mastronardi, L., Romero, C. (2015) Evaluating the FLQ and AFLQ Formulae for Estimating Regional Input Coefficients: Empirical Evidence for the Province of Córdoba, Argentina. Economic Systems Research 28(1), 21-37. DOI: 10.1080/09535314.2015.1103703 
11. Többen, J., Kronenberg T. (2015) Construction of Multi-Regional Input-Output Tables Using the Charm Method. Economic Systems Research 27(4), 487-507. DOI: $10.1080 / 09535314.2015 .1091765$

12. Широв А. А. Использование таблиц «затраты-выпуск» для обоснования решений в области экономической политики // Проблемы прогнозирования. 2018. № 6(171). С. 1225.

13. Межотраслевой анализ экономики Республики Бурятия на основе таблиц «затраты-выпуск» / З. Б.-Д. Дондоков, К. П. Дырхеев, Л. А. Мунаев [и др.] // Региональная экономика: теория и практика. 2014. № 28. С. 55-62.

14. Дондоков 3. Б.-Д. Разработка и апробация агрегированной модели суммарных расходов на примере Республики Бурятия // Фундаментальные исследования. 2020. № 2. C. 22-26. DOI: 10.17513/fr.42679

Статья поступила в редакцию 24.11.2020; одобрена после рецензирования 28.01.2021; принята к публикации 29.01.2021.

\section{DEVELOPMENT OF INFORMATION BASE FOR CALCULATIONS ON ENVIRONMENTAL POLLUTION USING AN INPUT-OUTPUT MODEL}

Zorikto B.-D. Dondokov

Dr. Sci. (Econ.), Chief Researcher

dzorikto@mail.ru

Darima Z. Ubonova

Junior Researcher

darimaub@mail.ru

Department of Regional Economic Research,

Buryat Scientific Center SB RAS

8 Sakhyanovoy St., Ulan-Ude 670047, Russia

Abstract. The article is devoted to the development of information base for input-output calculations on environmental pollution in the region. We have revealed the problem of poor accuracy of assessing the anthropogenic impact on the Baikal natural territory without taking into account the nature of the industry. It is substantiated the necessity of using the apparatus of input-output modeling to increase the level of detail and validity of calculations. We have analyzed the informational problems of compiling regional input-output tables. Formulas are given for calculating the multiplicative effects of changes in the volume of wastewater discharge into surface water bodies and emissions of pollutants into the atmosphere from stationary sources by type of business. It is shown the limited use of classical input-output model for assessing environmental pollution within the framework of business activity corresponding to the Russian Industry Classification System. We have substantiated the relevance of taking into account the environmental pollution by households within the input-output model of total expenditures.

Keywords: input-output model; region; the Republic of Buryatia; anthropogenic impact; environment; type of business; statistical data; input-output tables; multiplicative effects; endogenous parameters; exogenous parameters; households. 